\title{
Perceptions about civil war in Central Africa: Can war be justified OR SOLVE PROBLEMS?
}

\section{Authors:}

Kitambala Lumbu ${ }^{1}$

Peet van Dyk ${ }^{1}$

Alta van Dyk ${ }^{2}$

\section{Affiliations:}

${ }^{1}$ Department of Old

Testament and ANES,

University of South Africa,

South Africa

${ }^{2}$ Department of Psychology, University of South Africa, South Africa

Correspondence to:

Peet van Dyk

e-mail:

vdykpj1@unisa.ac.za

Postal address:

Department of Old

Testament and ANES, PO

Box 392, Unisa, 0003,

South Africa

Keywords:

Tutsi; Hutu; DRC; Rwanda; Church

\section{Dates:}

Received: 31 July 2009

Accepted: 06 Nov. 2009

Published: 16 Dec. 2009

How to cite this article: Lumbu, K., Van Dyk,

P. \& Van Dyk, A., 2009,

'Perceptions about civil war in Central Africa:

Can war be justified or solve problems?', Verbum et Ecclesia 30(2), Art. \#82, 6 pages. DOI: $10.4102 /$ ve.v30i 2.82

This article is available at:

http://www.ve.org.za
(C) 2009. The Authors. Licensee: OpenJournals Publishing. This work is licensed under the

Creative Commons

Attribution License.

\section{ABSTRACT}

Civil war and ethnic violence are major problems in Central Africa and have caused the death and displacement of millions of people over the years. The aim of this study was to investigate the perceptions of religious leaders, lecturers and students in theology at various tertiary institutions in Central Africa with regard to civil war in the region. A structured questionnaire was used to investigate participants' perceptions about and attitudes towards civil war. The questionnaire was completed by 1364 participants who originated or lived in the Democratic Republic of the Congo (DRC) and Rwanda. The results of the study illustrated the severe effect that civil wars had on the participants or their families and further indicated that Rwandans, Tutsis and males were more inclined toward justifying wars and seeing them as solutions for problems. The role of the Church in countering these perceptions is discussed.

\section{INTRODUCTION AND AIM}

Civil war and ethnic violence are major problems in Central Africa, with large-scale conflicts occurring since 1990 in the Democratic Republic of the Congo (DRC), Rwanda, Burundi and Uganda. These conflicts have caused death and large internal and external displacements. According to the report of the United Nations Office for the Coordination of Humanitarian Affairs (UNOCHA), published on 31 July 2008, an estimated 1250000 internally displaced persons (IDPs) had been registered in the eastern province of North and South Kivu and the district of Ituri (Province Orientale) in the DRC alone. These figures further show that there have not been substantive changes in this situation compared to the first quarter of the same year. In the second quarter of 2008 a staggering 65400 persons (4\% over the estimated total) were newly displaced and/or had been displaced for longer but their status only became accessible during the reporting period. At the same time some 65000 people returned to their areas of origin in South Kivu and Ituri. Many displaced people are also being harboured in refugee camps in neighbouring countries (externally displaced persons [EDPs]).

The disrupting influence of the displacements and conflicts has caused major social problems, which also involve the Church. In such a situation the potential positive influence of religious leaders (and future leaders or students) in breaking the cycle of violence cannot be overestimated. In order to try and mobilise religious leaders against possible future violence, this survey was conducted to assess current views and perceptions about violence in Central Africa. Based on this assessment suggestions will be made on how these perceptions may be addressed through theological education.

The purpose of the research was to explore the perceptions of religious leaders and lecturers and students of theology with regard to civil war and ethnic violence in the DRC and Rwanda, focusing on the following aspects:

- To what extent have the participants been affected by civil wars or conflicts during the past 20 years?

- According to them, what were the main causes of the civil wars?

- Can civil wars be justified?

- Do they think that civil wars are sometimes necessary to solve political and social problems?

- How do they think civil wars and conflicts can be avoided in future?

Following is a brief historical survey of the conflict in Central Africa and the increasing polarisation between the Tutsi and Hutu peoples, especially in Rwanda and Burundi, and how this has also had detrimental effects on the situation in the DRC. Biblical views on war will also be discussed.

\section{HISTORICAL BACKGROUND TO THE CONFLICT}

The conflict in Central Africa (and specifically Rwanda) has a long and complex history, with its roots in precolonial and colonial history. When the kingdom of Rwanda took shape in precolonial times, the region comprised three distinct groups: the Hutu, Tutsi and Twa. The main difference among these groups was in terms of their socio-economic lifestyle: The Hutus were primarily cultivators, the Tutsi cattle owners and the Twa hunter-gatherers. To promote political stability it was expected of the king to marry wives from all three communities (Gakunzi 1996:3-4).

However, when the first European colonists arrived in the 1900s in Rwanda, they found the country weakened and destabilised by the fact that one clan (the Tutsi) dominated the leadership and refused to pass on the leadership to one of the other two groups (Gakunzi 1996:4). The German colonial government further contributed toward the division among the Rwandan society by promoting the idea that the Tutsi was a 'lordly' race, partially descended from either Semitic or European ancestors. On the other hand, the Hutu group was considered a 'lazy' people and only fit for being labourers or slaves. The German colonial government therefore supported the Tutsi leadership and entered into an alliance with them (Gakunzi 1996:4). 
Perceptions among certain Tutsis are also that missionary work in the African Great Lakes region (especially by Catholic missionaries since 1880) caused an increased tension between the Tutsis and Hutus. According to them the Tutsi resisted conversion (due to their supposed Jewish origin) while the missionaries were more successful among the Hutu. In an effort to reward their conversion, the Catholic Church often confiscated traditional Tutsi land and awarded it to the recently converted Hutu tribes, thus beginning a conflict that has lasted into the 21st century (Berg 2003).

The bad blood between the Tutsi and Hutu was exacerbated when the Belgians assumed control of Rwanda and Burundi following World War I. They continued to promote the Tutsi over and against the Hutu and retained the hierarchical classification of the population into either Tutsi or Hutu (Berg 2003).

However, during the drive for independence in Africa (during the late 1950s) the Tutsi were in favour of independence from Belgium, causing the colonial power to suddenly switch its alliance from the Tutsi to the Hutu. It therefore allowed the majority Hutu to assume control of the government through universal elections. In the 1960s the Rwandan monarchy was overthrown and a republic headed by Gregoire Kayibanda was established. His Hutu-dominated regime persecuted the Tutsi, who in many cases were forced to flee to neighbouring countries such as Uganda and the DRC.

In 1973 when many Tutsis were fired from private and public institutions and young Tutsis were molested and threatened in schools and colleges, the situation in Rwanda exploded, leading to the overthrowing of the government by Habiarimana, an army officer who promised new national unity (Gakunzi 1996:5). Unfortunately this did not happen and various forms of persecution persisted under his regime, causing many of his opponents (mostly Tutsi) to be imprisoned or to flee to neighbouring countries such as Uganda. When the Tutsi in Uganda were pressurised by the Ugandan government to return to Rwanda, the Rwandan Patriotic Front (RPF), a rebel group of Tutsi refugees, was formed and invaded Rwanda in 1990.

The resulting Rwandan Civil War vastly increased the ethnic tensions in the country, which included the displacement of large numbers of Hutu in the north (by Tutsi rebel forces) and periodic localised ethnic cleansing of Tutsi to the south. Eventually the Arusha Accord (1993) arranged a cease-fire, but in 1994 the Rwanda genocide followed when the country experienced mass killing of hundreds of thousands of Tutsis (and Hutu political moderates) by Hutus. Over the course of approximately 100 days at least 500000 people were killed. ${ }^{1}$

Another genocide occurred earlier (1972) in the neighbouring country of Burundi, but this time against the Hutu population. In this killing an estimated 500000 Hutus died at the hands of Tutsis. In 1993, Burundi's first democratically elected president, Melchior Ndadaye (of Hutu descent), and his successor were assassinated by Tutsi officers. This sparked a period of civil strife in Burundi between Hutu political structures and the Tutsi military in which an estimated 800000 Burundians died. During this conflict there were indiscriminate mass killings, first of Tutsis and then of Hutus (Lemarchand 1996).

Within the DRC the Tutsi forces of the National Congress for the Defence of the People (CNDP) rebel group in the north-eastern regions are considered as outsiders from Rwanda by the local Congolese inhabitants. So the ethnic conflict existing within Rwanda and Burundi has to a large extent also become part of the conflict in the DRC.

In summary one can say that colonial powers in Central Africa exacerbated the precolonial situation by establishing

1. However, many estimates indicate a death toll of between 800000 and 1 million, which could be as high as $20 \%$ of the total population. multicultural societies that often came about because of the establishment of arbitrary colonial boundaries (Pakenham 1991). One of the main consequences of the resulting conflicts was a huge number of IDPs and EDPs, as mentioned in the introduction. This is a continuing problem in Central Africa with a cycle of violence that has become endemic and needs urgent attention.

\section{BIBLICAL VIEWS ON WAR}

As suggested in the introduction, Christian leaders can potentially play a significant role in combating violence and conflict in Central Africa. To be able to play this role they would, however, in the first place need to be convinced that the Bible condemns violence and in the second place spread this message of peace effectively to their respective communities.

Unfortunately the biblical (and especially the Old Testament) views about war and conflict are to some extent ambiguous. For example, in the early Christian Church Marcion denounced the Old Testament for being 'unchristian' (Gunneweg 1978:115-117) while many other scholars have criticised the Old Testament for being a book about wars, killing and raping (cf. Van Dyk 2003:96).

Niditch (1993) described the Old Testament's complex treatment of war and violence by identifying seven different ideologies regarding war, ranging from justification of war (under certain conditions) to implicit and explicit criticism of violence. She sees these coexisting, contradictory and overlapping ideologies with regard to war as an important literary device that expresses the psychological paradoxes within a community and even within the same person.

Elliot (1993) made the important point that one should understand the Bible against the social context and belief systems of its time and Van Dyk (2003:110-111) argued that individual biblical texts should be interpreted against the broader ethical principles of the Bible, even if this sometimes mean that one should read 'against the grain' of a specific text (cf. Clines 1992:82-83).

The fact that the broader Old Testament ideal is not one of war and conflict but one of peace was expressed by Hanson as follows:

If one were to choose a single word to describe the reality of which God created the world, and in which He seeks to sustain the community of those who respond to his initiating grace ... that would be "shalom".

(Hanson 1984:341)

Chester (1989:470-472) emphasised that the Hebrew word shalom is much broader than the English word peace and is much more than an empty slogan. It not only denotes the cessation of conflict but also expresses the onset of universal harmony and happiness.

Van Dyk (2003:102) further pointed toward the Old Testament imperative to love the non-Israelite or sojourner. In this regard the Old Testament is a major advance over the usual ethical principles of ancient and traditional societies by demanding not only that sojourners should be protected but also that they should be 'loved', that they should be included in the Israelite festivals and that provision should be made for their livelihood.

Van Dyk (2003:105-107) also criticised the easy way in which religious people often 'succumb' to the view that wars and conflicts can be justified by viewing them as an instrument of God's justice or by romanticising them as heroic acts.

Although the Old Testament view of war and conflict is complex, this fact should not, however, detract from its overall condemnation of violence and its imperative for peace. This research was an attempt to understand current perceptions about violence and conflict among Christian leaders in Central 
Africa and propose to what extent these should be rectified in the light of the broader biblical imperative for peace.

\section{METHOD}

A structured questionnaire (available in English and French) was used to conduct a survey among religious leaders and students and lecturers in theology in Central Africa. It assessed the perceptions of these religious participants about the civil war and ethnic violence, specifically in the DRC and Rwanda.

\section{Sample}

Questionnaires were completed by church leaders, lecturers and students (at various private and public theological training institutions) in Central Africa during 2007. Participants from different backgrounds and religious denominations as well as from urban and rural areas, originating or living in the DRC and Rwanda, were included in the survey. The sample should be seen as a convenient sample ( $c f$. Coolican 2004:42) and is not necessarily representative of all church leaders and theology lecturers and students in the region. The results can therefore not necessarily be generalised to all religious leaders in the DRC and Rwanda.

During sampling it was, however, attempted to avoid any bias in terms of religion, gender, age, ethnicity, occupation or geographic location. Participants from two countries, representing 31 tribes (language groups), were included in the sample of 1364 participants who completed the questionnaire.

\section{Measuring instrument: Structured questionnaire}

A structured questionnaire was used to obtain the following information from the participants:

- Biographical information (i.e. country of permanent residence, gender, ethnic group and religious affiliation).

- Likert scales (ordinal 5-point scales, ranging from 'strongly agree' to 'strongly disagree') were used to measure participants' perceptions and attitudes in terms of the following:

- Justification of war.

- Did the war solve problems?

- Participants were further asked to indicate

- whether their ethnic group had been involved in civil war during the past 20 years and, if so, how they were affected by it;

- what, according to their ethnic group, were the main causes of the war; and

- in what way their group could in future help to prevent conflicts.

A few participants needed assistance with the completion of the questionnaire, but the majority of the respondents (because of their generally high level of education) filled in the questionnaires anonymously and without any help.

\section{Statistical analysis}

The closed questions were coded and analysed using the Statistical Package for the Social Sciences (SPSS). Descriptive and inferential statistical techniques were used to analyse the data. The level of significance was set at 0.01 . The non-parametric Mann-Whitney $U$ test was used to determine possible group differences with regard to the Likert scales. The reasons for the choice were that because these scales are non-standardised, they do not necessarily adhere to normality and do not measure interval data (cf. Coolican 2004:363).

In all cases size effects were calculated to determine how strong effects really were. Pooled variances (for unequal sample sizes) were used in the formula to calculate size effects. ${ }^{2}$ Cohen's (1988) scale was used to interpret the results obtained for size effects ( $c f$. Coolican 2004:384-385)

2.Size effect is calculated by using the formula $d=\frac{(\mu 1-\mu 2)}{\sigma^{2}}$ (Coolican 2004:384)
TABLE 1

Ethnic groups

\begin{tabular}{lrr}
\hline ETHNIC GROUP & FREQUENCY & PERCENTAGE \\
\hline Tutsi & 86 & 6.3 \\
Hutu & 257 & 18.8 \\
Luba & 329 & 24.1 \\
Nande/Yira & 281 & 20.6 \\
Other & 411 & 30.1 \\
\hline TOTAL & $\mathbf{1 3 6 4}$ & $\mathbf{1 0 0}$ \\
\hline
\end{tabular}

TABLE 2

Position in the Church or educational institution

\begin{tabular}{lrr}
\hline STATUS & FREQUENCY & PERCENTAGE \\
\hline Undergraduate student & 1133 & 85.1 \\
Postgraduate student & 74 & 5.5 \\
Lecturer & 21 & 1.6 \\
Church leader & 103 & 7.7 \\
\hline TOTAL & $\mathbf{1 3 3 1}$ & $\mathbf{1 0 0 . 0}$ \\
\hline
\end{tabular}

\section{RESULTS}

\section{Demographic features of participants}

A total of 1364 people participated in the survey, of whom 370 $(27.1 \%)$ were women and $986(72.3 \%)$ men. Of the participants $151(11.1 \%)$ resided permanently in Rwanda and 1213 (88.9\%) in the DRC. Participants from 31 ethnic groups completed questionnaires, but smaller language groups were lumped together for statistical purposes. Participants were, therefore, divided into the following ethnic groups: Tutsi, Hutu, Luba, Nande/Yira and others (see Table 1 for frequencies per group).

Because the survey was primarily conducted among church leaders and lecturers and students of tertiary educational institutions, the education level of participants was generally high. The frequencies of the positions in the Church or educational institutions reported by the participants are reported in Table 2.

The participants came from various church denominations. However, because it was a convenient sample, the frequencies of church denominations were not representative of the DRC or Rwanda and were especially biased towards the Seventh Day Adventist denomination (see Table 3 for frequencies of denominations).

The demographic data indicated that the sample included a wide variety of people associated with various theological training institutions and representative of most of the large Christian groups within the DRC and Rwanda.

TABLE

Denominations

\begin{tabular}{lrr}
\hline DENOMINATION & FREQUENCY & PERCENTAGE \\
\hline Catholic & 368 & 27.0 \\
Protestant & 335 & 24.6 \\
Adventist & 561 & 41.1 \\
Other & 71 & 5.2 \\
None & 8 & 0.6 \\
\hline TOTAL & $\mathbf{1 3 4 3}$ & $\mathbf{9 8 . 5}$ \\
\hline
\end{tabular}


TABLE 4

Relative importance of effects

\begin{tabular}{lr}
\hline EFFECT & PERCENTAGE OF PEOPLE AFFECTED \\
\hline Loss of possessions or land & $49.0 \%$ \\
Displaced or became refugee & $42.2 \%$ \\
Personally or family member wounded & $36.7 \%$ \\
Involved in fighting & $8.7 \%$ \\
Loss of political power & $7.8 \%$ \\
\hline
\end{tabular}

The effects of civil war, views of participants regarding the civil wars in Central Africa and especially how these perceptions may differ among various groups will be considered next.

\section{Effects of civil war}

Three-quarters of the participants indicated that they had been in some way affected by civil war or conflict in the region during the past 20 years, while $25.2 \%$ had not been directly affected. The majority of the participants who had been affected by the civil war suffered the loss of their possessions or land, were displaced or became refugees and were either wounded themselves or had close family members being wounded. It is of importance to note that one out of every 11 participants reported that they had been involved in the fighting themselves. Interestingly, loss of political power was not perceived as having a major effect on the participants' lives (See Table 4 for frequencies of the effects of civil war on the participants).

It is clear from Table 4 that a large proportion of the participants experienced severe effects from the civil war or conflict. This paints an extremely serious picture of people's lives being disrupted in some way. Although some of them had been actively involved in fighting, most of the participants were passive victims of the war.

\section{Causes of civil war}

Participants were asked to rate the main causes for the civil war in their region from 1 to 3 . The ranks were then converted into a scale with the following results (see Figure 1).

From Figure 1 it is clear that the main causes of wars and conflicts were perceived as follows: ethnic or tribal factors $(43 \%)$, economic factors $(41 \%)$, outside groups $(39 \%)$ and power struggles (37\%). Lesser causes were listed as group suppression $(25 \%)$, disagreement among leaders $(22 \%)$, corruption $(18 \%)$ and other unspecified reasons ( $9 \%)$.

The high rank of outsiders as a cause for conflict in Figure 1 can possibly be attributed to the fact that the Tutsi forces of the CNDP rebel group in the north-eastern DRC are considered as outsiders from Rwanda by the local Congolese inhabitants. It should also

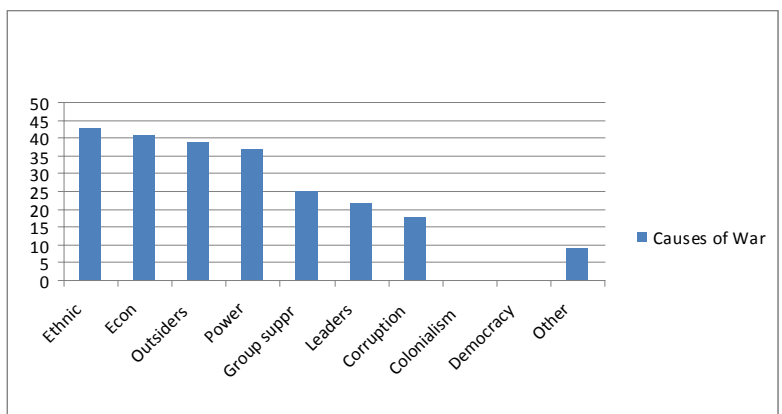

FIGURE

Causes of war be noted that views regarding the possible justification of civil war differed significantly between the Tutsi ethnic group and all the other ethnic groups (see below).

Fights for democracy and remnants of colonialism were not chosen by any participant as a possible cause of war. This is an important finding in the light of the fact that scholars often identify remnants of colonialism as possible causes for conflict in Africa (e.g. Shah 2009).

\section{Justification of war}

The results showed that $23.4 \%$ of the participants thought that the conflict (in which their ethnic group or their neighbours were involved) was justified, while $15.4 \%$ were uncertain and $59.4 \%$ thought that it was not justified. Although the majority of participants were therefore negatively inclined toward civil wars in the region, it is still disconcerting that more than $20 \%$ agreed or strongly agreed with the notion that these wars could be justified.

Perceptions about the possible justification of civil wars differed significantly among different groups. Note that only significant differences $(p<0.01)$ and size effects above 0.3 are reported below:

- Rwandans were more inclined to think that the civil war or conflict was justified than people in the DRC $(\mathrm{U}=72$ 693; $\mathrm{p}=$ 0.002 ; size effect $=0.309$ [small to medium effect]).

- Males leaned more toward seeing wars as justified than females $(\mathrm{U}=72$ 693; $\mathrm{p}=0.002$; size effect $=0.338$ [small to medium effect]).

- Ethnic groups differed significantly in terms of their views of the justification of the civil wars. The Tutsi group was much more inclined to view the civil wars as justified in contrast to the other ethnic groups. Table 5 summarises the ethnic differences.

Other smaller differences existed among other ethnic groups but with relative small effect sizes and are thus not reported.

It was, therefore, mainly the Tutsi ethnic group that was more inclined to view the civil wars as justified while the other groups were more inclined to perceive them as unjustified. As suggested above, the Tutsi group is often regarded as 'outsiders' in the north-eastern DRC and is blamed by other groups as a major cause for the civil war within the DRC.

\section{Did the wars solve problems?}

The second main focus of the research was to determine to what extent the participants perceived civil wars as solutions to political and other problems. The results showed a highly significant correlation between the perception of just wars and the view that it solved problems (Spearman, $\rho=0.264 ; \mathrm{p}<$ $0.000)$.

TABLE 5

Differences in perceptions about justification of wars among ethnic groups

\begin{tabular}{|c|c|c|c|}
\hline $\begin{array}{l}\text { MORE } \\
\text { INCLINED TO } \\
\text { JUSTIFY }\end{array}$ & $\begin{array}{r}\text { LESS INCLINED TO } \\
\text { JUSTIFY }\end{array}$ & SIGNIFICANCE & SIZE EFFECT \\
\hline Tutsi & Hutu & $\begin{array}{l}U=8468 \\
p=0.001\end{array}$ & 0.469 (medium) \\
\hline Tutsi & Luba & $\begin{array}{r}U=10793 \\
p=0.002\end{array}$ & 0.418 (medium) \\
\hline Tutsi & Nande/Yira & $\begin{array}{l}U=8646 \\
p<0.000\end{array}$ & 0.576 (medium) \\
\hline Tutsi & $\begin{array}{r}\text { Combined smaller } \\
\text { groups }\end{array}$ & $\begin{array}{r}U=11646 \\
p<0.000\end{array}$ & $\begin{array}{r}0.631 \text { (medium to } \\
\text { large) }\end{array}$ \\
\hline
\end{tabular}


TABLE 6

Differences among ethnic groups in perceiving wars as solutions to problems

\begin{tabular}{|c|c|c|c|}
\hline $\begin{array}{l}\text { MORE INCLINED } \\
\text { TO SEE AS } \\
\text { SOLUTION }\end{array}$ & $\begin{array}{r}\text { LESS INCLINED } \\
\text { TO SEE AS } \\
\text { SOLUTION }\end{array}$ & SIGNIFICANCE & SIZE EFFECT \\
\hline Rwanda & DRC & $\begin{array}{r}U=60782 \\
p=0.000\end{array}$ & 0.709 (large) \\
\hline Tutsi & Hutu & $\begin{array}{l}U=7582 \\
p=0.000\end{array}$ & 0.533 (medium) \\
\hline Tutsi & Luba & $\begin{array}{l}U=9377 \\
p=0.000\end{array}$ & 0.715 (large) \\
\hline Tutsi & Nande/Yira & $\begin{array}{l}U=6598 \\
p=0.000\end{array}$ & $\begin{array}{r}1.136 \text { (extremely } \\
\text { large) }\end{array}$ \\
\hline Tutsi & $\begin{array}{r}\text { Combined } \\
\text { smaller groups }\end{array}$ & $\begin{array}{r}U=10286 \\
p=0.000\end{array}$ & 0.935 (large) \\
\hline
\end{tabular}

As with the perceptions about the justification of war, significant differences also existed among different ethnic groups in terms of their views about war as a possible solution to problems. Only significant differences among ethnic groups and size effects above 0.3 are reported in Table 6 .

It is clear from Table 6 that it is mainly the Rwandans and the Tutsi ethnic group that perceived war as a solution to problems. Differences among male and female, status/education levels and churches were either not significant or effect sizes were too small to report.

\section{How to prevent future conflict}

Participants were in the last instance asked to rate possible preventative measures in terms of importance (from 1 to 3 ) and these results were then converted into a scale with the following results, as illustrated in Figure 2.

From Figure 2 it is clear that the participants regarded positive measures as much more valuable than negative measures as a way to solve and prevent future conflict in the region. Most of the participants believed that praying for peace $(47 \%)$ and working towards democracy and fair and free elections (42\%) will solve conflict or prevent future conflict. Some believed that conflict can be solved or prevented by educating other ethnic groups $(25 \%)$ and by facilitating negotiations $(21 \%)$.

Further important results to note were that nobody regarded force as a way to resolve or prevent future conflict and that nobody thought that UN intervention or measures to fight corruption would be effective in preventing future conflicts.

\section{DISCUSSION}

The extent to which participants were directly or indirectly

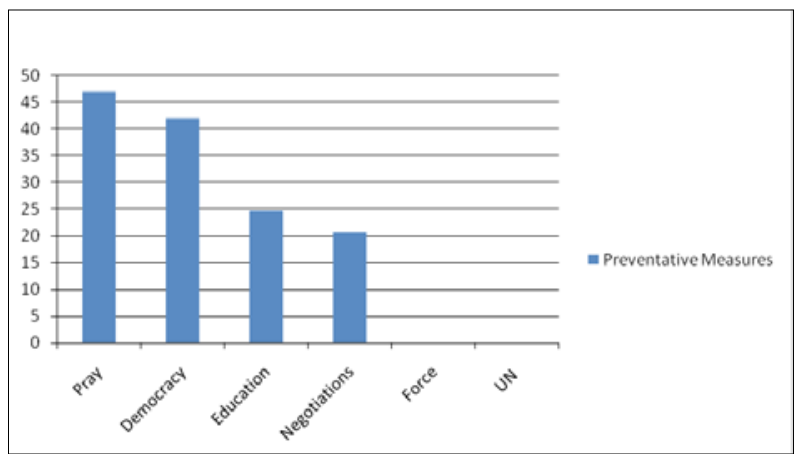

FIGURE 2

Perceived importance of possible preventative measures affected by the civil wars and conflict in Central Africa is a confirmation of how deep the impact of the conflict is. This emphasises the importance of trying to break the cycle of violence. Especially the Tutsi-Hutu conflict that dates back many decades formed people's perceptions about the causes of the wars as being mainly attributable to ethnic and economic factors, outsiders and the struggle for power. All these factors can be explained in terms of the economic and power struggle between the Hutu and Tutsi (and other groups) that has scorched this part of the continent for so long. The fact that outside forces are 'blamed' for the violence is in the first place explainable by the fact that it is primarily seen as an ethnic conflict (which automatically defines the parties in terms of 'in' and 'out' groups) and the fact that Tutsi rebel groups have often in the past launched wars from neighbouring countries into Rwanda and also the DRC.

The fact that the Tutsi group has during the past five decades lost political and economic power in Rwanda and Burundi and that its rebel forces have been to some extent successful in regaining some of the lost power may explain why Tutsis are much more inclined to see civil war and conflict as justified or solving problems. This may be especially true if they further adhere to the racist view that they are a 'superior' ethnic group that has the right to political power. This fact and the fact that the Hutu population has been increasingly suspicious since the late 1950s of a perceived plot by the Tutsi group to regain power and 'enslave' the Hutu have constantly fuelled the conflict.

Although the 'racial' separation can at least partially be ascribed to the historical role German and Belgium colonial forces played in the region, it is nonetheless interesting to note that colonialism as such was not perceived as a major factor in the conflict. Along a more cynical line this can probably be seen as an indication of how successful the colonial policy of 'divide and rule' has been in this region. On the other hand it is probably true that colonial racial policies are not the only factors to blame but that both precolonial and postcolonial factors have been instrumental in the Tutsi-Hutu conflicts.

The negative perceptions about United Nations (UN) forces and their possible positive role in helping to resolve the conflict in Central Africa is understandable in the light of the fact that UN forces are often perceived as outsiders who are not an uninterested or neutral force. For example, the presence of the $\mathrm{UN}$ in the DRC is not welcomed for multiple reasons (own observation):

- The local population feels that the UN plays the card of the aggressor or the card of the opposition.

- It seems as if the UN personnel is very well paid, and the perception is that they therefore wish to remain in the country for a longer period for financial gain.

- It further often seems to the locals that while the UN is in the region it exploits the natural resources, providing itself with additional financial gain. The view of many local inhabitants within the DRC is therefore that it is to the economic advantage of UN personnel to maintain conflicts in the region.

In contrast to the situation in the DRC, perceptions in Central Africa are that the UN has a different agenda in Rwanda where it plays the card of the government by supporting the government forces. Gakunzi (1996:10) evaluated the role of the UN as follows: 'What happened in Rwanda demonstrated the incredibility and the ineffectiveness and inefficiency of the United Nations.' The potential role of UN forces in resolving the conflicts in Central Africa is therefore perceived as extremely limited in both Rwanda and the DRC.

In respondents' suggestions on how their ethnic group could best help to solve or prevent future conflict (such as praying for peace, working towards democracy and educating other ethnic groups), the need for assistance from organisations such as 
the Church became apparent. Within this scenario the Church and its leaders can potentially play a significant and positive role in alleviating tension among groups. Following are some recommendations in the light of the results of our research.

\section{WHAT CAN THE CHURCH DO?}

The Church and the Bible's message of peace can potentially play an important role in solving the conflict in Central Africa. The time has come for the Church to educate the heart and the soul of church members and church leaders, that is to educate the heart and the soul of those who will become presidents, ministers, members of parliament, college and university lectures and church leaders. If the heart is not well educated, people will have no love for others. This is education for life.

Nicole (1982:7) summarised the role of the Church as follows:

- Every church leader and member is called to come out of this world and rise above the conflict and serve the Lord.

- The Church must be a church of peace, not the church of pieces, by teaching members and the community to be people of peace.

- The Church must live and share the 'shalom Yahweh' because peace is a result of God's activity in covenant and is the result of righteousness (Isaiah 32:17).

- The Church in Central Africa must be a loving church and be constituted of God's people who realise that God, in creating all things, has acted in love: God's calling of Abraham to be the father of a people serving as a light to the nations is an act of love; God's freeing the enslaved Hebrews from Egypt to a new life is an act of mercy. This needs to be a teaching experience of the people of God, living in this part of the world.

- The Church in Central Africa must train communities to be God-fearing communities.

In the light of the current findings, the following can be added to Nicole's suggestions:

- The Church must lead by example to illustrate what democracy, fairness and freedom mean in practice.

- The Church should play a role in facilitating diversity training whereby groups can learn to respect and trust each other.

- Education should not only be about 'educating the outside group', as suggested by some participants of this study, but attention should also be given to re-educating the 'inside' group to better understand the 'outside' group.

- The Church should offer post-traumatic stress counselling for the many victims of war and violence and assist them to repair their trust in the human race.

- The Church should address the perception of 'just' wars and the view that it may be a solution to problems. This can be done by emphasising the negative effects of wars and the fact that they mostly serve the short-term self-interest of a specific ethnic group, leader or country. The ways in which so-called 'just' wars are rationalised should also be exposed by offering a multi-ethnic perspective.

In her teaching the Church cannot take sides and should stress the fact that the use of force (even though it may sometimes seem like an attractive alternative) often fails to solve problems and only creates more problems and more unrighteousness in the world in the long term. The fact that no participant supported the idea of resolving future problems by using force is a positive indication that the message of peace already plays a role, but it should be emphasised and further underscored by teaching and ministry.

From the results of this study it became clear that the Church and theological institutions will have to pay special attention to certain groups that are more inclined towards justifying war and violence (especially the Rwandans, Tutsis and males). This should be done in such a loving way that it does not imply that the Church is targeting the Tutsi group or is blaming any specific group for the conflict because this would merely serve to strengthen old divisions.

\section{REFERENCES}

Berg, I.M, 2003, Jews in Central Africa, viewed 25 July 2009, from http://www.kulanu.org/tutsi/jews-africa.php

Chester, A., 1989, 'The concept of peace in the Old Testament', Theology XCII(750), 466-481.

Clines, D.J.A., 1992, 'Images of Yahweh: God in the Pentateuch' in R.L. Hubbard, R.K. Johnston \& R.P. Meye (eds.), Studies in Old Testament Theology, 79-98, Word Publishing, Nashville.

Cohen, J., 1988, Statistical power analysis for the behavioral sciences, Academic Press, San Diego.

Coolican, H., 2004, Research methods and statistics in Psychology, 4th edn., Hodder \& Stoughton, London.

Elliott, J.H., 1993, What is social-scientific criticism? Fortress Press, Minneapolis.

Gakunzi, D., 1996, 'Rwanda: The roots of a genocide', Propeace 1 3-10.

Gunneweg, A.H.J., 1978, Understanding the Old Testament, SCM Press, London.

Hanson, P.D., 1984, 'War and peace in the Hebrew Bible', Interpretation XXXVIII(4), 341-362.

Lemarchand, R., 1996, Burundi: Ethnic conflict and genocide, Woodrow Wilson Centre and Cambridge University Press, New York.

Nicole, J.M., 1982, Précis de l'Histoire de l'Église, Éditions de l'Institut Belgique: Ngonget-Marne.

Niditch, S., 1993, War in the Hebrew Bible, Oxford University Press, New York.

OCHA Regional Office for Central and East Africa, 2008, 'Displaced populations report', OCHA, January-June 2008 , Issue 3, viewed 13 May 2009, from http://www.ochaonline. un.org.

Pakenham, T., 1991, The scramble for Africa 1876-1912, Jonathan Ball, Johannesburg.

Shah, A., 2009, Global issues: Conflicts in Africa - Introduction, viewed 14 May 2009, from http://www.globalissues.org/ article/84/conflicts-in-africa-introduction\#TheLegacyofEur opeanColonialism.

Van Dyk, P.J., 2003, 'Violence and the Old Testament', Old Testament Essays 16(1), 96-112. 